\title{
Penetrating Injuries to the Lung and Heart: Resuscitation, Diagnosis, and Operative Indications
}

\author{
Mark F. Scott ${ }^{1} \cdot$ Jack A. Sava ${ }^{2}$
}

Published online: 23 September 2015

(C) Springer International Publishing AG 2015

\begin{abstract}
Penetrating injuries to the thorax have the potential to disrupt two vital life-sustaining systems: the respiratory and the cardiovascular system. These injuries have the potential to be rapidly fatal and thus a rapid, organized, and logical approach to the evaluation and resuscitation of these patients is critical. This article briefly reviews the basic pathophysiology of penetrating chest wounds and the evaluation of both stable and unstable patients after penetrating chest injury. The recent literature is reviewed, including recent findings on screening for occult penetrating cardiac injuries, the use of needle decompression for pneumothoraces, and the expanding role of ultrasonography in the evaluation of penetrating thoracic trauma. Our goal is to review the initial management and resuscitation of patients with penetrating wounds to the thorax, with an eye toward the injuries most likely to rapidly result in death.
\end{abstract}

Keywords Pneumothorax $\cdot$ Hemothorax $\cdot$ Penetrating cardiac injury: penetrating lung injury $\cdot$ Diaphragm injury

This article is part of the Topical Collection on Penetrating Injuries to the Heart and Lung.

Jack A. Sava

Jack.A.Sava@medstar.net

Mark F. Scott

mscott8@nshs.edu

1 Department of Surgery, North Shore University Hospital, 300 Community Drive, Manhasset, NY 11030, USA

2 Department of Trauma Surgery, MedStar Washington Hospital Center, 110 Irving St NW, 4B-39, Washington, DC 20010, USA

\section{Introduction}

While penetrating injuries to the thorax can be highly lethal, for patients who reach the hospital alive, mortality in recent military and civilian series has ranged from 8.4 to $18.0 \%$ [1-4]. Overall, injuries to the thorax account for $37 \%$ of deaths associated with penetrating trauma [5]. It is clear that to maximize the chance for patient survival, there is little room for error in the diagnosis and management of these injuries.

\section{Pathophysiology}

Regardless of body region, penetrating injury is broadly categorized into stab wounds and ballistic injuries. Ultimately, a comparison of the bullet and knife wound management demonstrates more similarities than differences. However, there is a rationale for approaching them differently. First, gunshot wounds - especially from high-velocity weapons - are associated with more tissue injury, due to their greater kinetic injury. Second, stab wounds may be somewhat more predictable in their course and in the proximity of internal injuries to corresponding skin wounds. However, both of these differences represent potential pitfalls if they lead to underestimation of knife injury, which can be massively destructive and can occur far from the external wound.

\section{Organs Injured}

Compared to blunt trauma, penetrating trauma is far less likely to cause significant structural damage to the chest wall, with the exception of shotgun injury and some high-velocity wounds. Lethal thoracic injury typically results from lung, heart, intercostal artery, or great vessel injury. The extreme time-sensitivity of these injuries leads the paradoxical observation that in remote or poorly developed care systems where 
pre-hospital times are inordinantly long, the survival rate of those who arrive alive will be unusually high, since the most fragile and severely injured patients will die en route [6].

\section{Imaging in Penetrating Thoracic Trauma}

\section{Ultrasonography in Penetrating Thoracic Trauma}

Over the past 2 decades, the Focused Assessment with Sonography in Trauma (FAST) exam has become the initial imaging test of choice in truncal trauma and is taught as a part of the Advanced Trauma Life Support (ATLS) protocol developed by the American College of Surgeons. On the basis of studies demonstrating ultrasound's superiority to supine chest radiography (CXR) for the detection of hemothorax and pneumothorax, the extended-FAST exam (e-FAST) has been developed, which adds examination of bilateral pleural spaces to the standard pericardial, peri-hepatic, peri-splenic, and pelvic views of the FAST exam. Ultrasonography as an initial test is significantly faster than CXR, taking less than $1 \mathrm{~min}$ in some studies [7], and it can identify a variety of life-threatening injuries in multiple body cavities. The e-FAST literature suggests that the sensitivity of e-FAST is significantly higher than CXR for pneumothorax and rivals that of subxiphoid pericardial window for hemopericardium.

Since 2011, seven prospective evaluations [7-13] and three meta-analyses $[14,15,16 \cdot \bullet]$ have compared the extended FAST exam (e-FAST), which includes examination of bilateral pleural spaces for pneumothorax, to CXR and CCT. In the most recent meta-analysis, e-FAST has a sensitivity of $78.6 \%$ (95\% CI, 68.1 to 98.1) for the detection of pneumothorax, whereas supine CXR had a sensitivity of only $39.8 \%$ (95\% CI, 29.4 to 50.3) [16••].

Two studies have examined the value of bedside ultrasound in the diagnosis of hemopericardium. The first was a prospective, multicenter study by Rozycki et al. in 1999, which examined 261 patients and reported a sensitivity of $100 \%$ for ultrasound diagnosis of hemopericardium as compared to subxiphoid pericardial window (SPW) [17]. A weakness of this study was the low incidence of penetrating cardiac injury (PCI) in the study population (29 out of 261 patients). A second, prospective comparison was recently published by Nicol et al., comparing ultrasound to SPW in 172 patients with penetrating thoracic wounds, with $135 \mathrm{PCI}$ amongst them [18••]. Although they found that the sensitivity of ultrasound was $87 \%$, which is lower than the first study, the authors identified two factors that appeared to account for the majority of the false-negative exams. In 6 of the 18 false-negative exams, pneumomediastinum or pneumopericardium was present on ultrasound which resulted in an equivocal test due to impaired visualization. Of the remaining 12 false-negatives, 11 had hemothoraces which other authors have noted can decrease the sensitivity of ultrasound for detecting hemopericardium due to decompression of the cardiac injury into the hemothorax [19, 20]. There was a single patient who had two negative ultrasound examinations, was discharged home, and returned with a symptomatic pericardial effusion.

\section{Chest Computed Tomography in Penetrating Thoracic Trauma}

Chest computed tomography (CCT) is the "gold standard" for diagnosing hemothorax and pneumothorax, due to its ability to provide high-resolution cross-sectional imaging [16••]. In addition to providing excellent anatomic information regarding chest wall, pulmonary, and pleural space injuries, a recent study by Plurad et al. demonstrates that CCT is also highly sensitive for PCI. They examined 333 patients with penetrating thoracic injuries and found that, as with ultrasound, the finding of hemopericardium or pneumopericardium on CCT had a sensitivity of $76.9 \%$ for PCI [21]. When they further investigated the patients with "false-negative" CCT, all of them had CT findings that prompted emergent surgical exploration and prompt diagnosis of the injury, including the presence of large caked hemothorax, pneumomediastinum, mediastinal hematoma, or visible tracts in close proximity to the heart. Thus, when factoring in all of the clinically significant findings that changed management, they felt that CCT had a sensitivity of $100 \%$ [21].

\section{Resuscitation, Evaluation, and Management of the Stable Patient}

\section{Evaluation of the Stable Patient}

In hemodynamically stable patients, the initial evaluation is focused on identification of a number of occult injuries, including cardiac laceration, hemothorax and pneumothorax, diaphragm injury, and occult abdominal injury. Ultimately, the majority of thoracic injuries can be treated with tube thoracostomy alone, but the consequences of missed injury can be dire [22].

\section{Identification of PCI}

Significant cardiac injuries can present with stable vital signs, but delayed decompensation can be rapid and catastophic. Various authors have attempted to define a region of the thorax in which penetrating wounds should prompt a heightened level of suspicion for PCI, such as the "cardiac silhouette" or "precordium," [23, 24] "cardiac proximity," [25] "cardiac silhouette," "cardiac box," [26], and "cardiac zone." [18••] A weakness of all of these rules is that they can lead to an inappropriately low degree of clinical suspicion for PCI. 
Degiannis et al. found that the mortality of extra-precordial wounds was $25 \%$ compared to $4 \%$ for wounds to the precordium [27], suggesting that this bias exists and can negatively impact patient outcomes.

After completing the primary and secondary survey according to ATLS guidelines, all patients with penetrating thoracic wounds should be examined with FAST or e-FAST. In young, healthy patients, the presence of any amount of fluid within the pericardial sac should be considered a positive exam. In the event of an equivocal US, further evaluation for PCI is recommended, either with subxiphoid pericardial window (SPW) or chest computed tomography (CCT). In the event of a negative ultrasound, a CCT and/or repeat ultrasound at $24 \mathrm{~h}$ should be obtained if there is any hemothorax on CXR or ultrasound, and in any patient with high clinical suspicion of PCI $[18 \bullet \bullet$.

A recent study from the Nicol and colleagues suggests that pneumopericardium should be managed the same as hemopericardium. Nicol and colleagues studied 21 hemodynamically stable patients pneumopericardium found on CXR, ultrasound, or CCT. All of the patients were initially observed for $24 \mathrm{~h}$ prior to performing a delayed SPW. During that time, two patients developed tension penumopericardium requiring emergency SPW; an additional ten patients had hemopericardium at the time of the delayed SPW, four of whom underwent sternotomy. Two sealed cardiac injuries were found, neither requiring repair. Given the $50 \%$ coincidence of hemopericardium and the $10 \%$ incidence of delayed tension pneumopericardium, they concluded that any patient with pneumopericardium present on CXR, CT, or ultrasound should be further evaluated with SPW [28].

In the case of thoracoabdominal wounds, laparoscopic transdiaphragmatic pericardial window has been recently described by Smith et al. in a series of 393 patients with thoracoabdominal wounds and no indication for immediate laparotomy or sternotomy [29]. Diagnostic laparoscopy was performed, and if peritoneal violation was found, they converted to open laparotomy and pericardiotomy. In the $38 \mathrm{pa}-$ tients without peritoneal violation, laparoscopic transdiaphragmatic pericardiotomy was performed through the central tendon of the diaphragm. A negative exam was defined by visualization of clear fluid. One patient had no fluid and five had bloody fluid; in all six patients, cardiac injuries were identified, five of which required median sternotomy for repair. The diaphragmatic defect was not closed.

\section{Indications for Sternotomy in PCI}

In recent years, the question has been raised regarding whether the presence of hemopericardium after penetrating trauma mandates median sternotomy, based on the observed high rate of nontherapeutic sternotomy in hemodynamically stable patients without active bleeding at the time of SPW [30, 31]. To address this question, Nicol et al. have recently published a prospective randomized evaluation where 111 hemodynamically stable patients who had undergone SPW with no evidence of active bleeding were then randomized either undergo sternotomy or observation [32•]. They found no injuries at sternotomy that require repair, although four out of 55 patients randomized to sternotomy had full-thickness injuries to the heart that were judged to be "completely sealed." None of the patients undergoing drainage alone required subsequent sternotomy. An important caveat of this study is that they examined a highly selected group of patients at an institution that treats a high volume of PCI (111 out of 348 patients undergoing surgery for PCI during the 7.5 years of the study). This management strategy rests on the premise that "sealed" cardiac injuries will never re-bleed - an assumption that will only be proven with more experience with this approach. Less experienced surgeons should exercise great caution before considering nonoperative management of a PCI. A delayed bleed from an unrepaired injury can be catastrophic.

\section{Pneumothorax and Hemothorax}

Blood or air in the pleural space may diagnosed clinically or using imaging. The noise and distraction of a trauma resuscitation often make a nuanced chest exam difficult. In a stable, well-oxygenated patient, it is usually safe to wait for imaging confirmation before placement of a chest tube if only subtle abnormalities are present. As discussed above, ultrasound has sensitivity in detection of pneumothorax that exceeds supine CXR. Nonetheless, CCT is the gold standard, detecting even tiny air or blood collections not seen on CXR. If a hemothorax is identified, management with tube thoracostomy drainage will be sufficient in $96 \%$ of patients without cardiac injury [33]. Traditionally, a 36-40 Fr tube has been inserted; however, recent evidence suggests that smaller tubes of 28-32 Fr may be equally effective at evacuating the blood [34]. More recently, a small randomized trial compared 14 Fr percutaneous pigtail catheter drainage to $28 \mathrm{Fr}$ traditional chest tubes for traumatic pneumothorax; there were no differences in the rate of successful evacuation, duration of drainage, or complications; however, the pigtail catheters were associated with significantly less pain than the traditional tubes [35••].

Over the years, several studies have questioned whether pneumothorax seen on CCT but not on CXR needs treatment. Occult pneumothoraces are identified on CCT in 5-15\% of patients [36]. A recent meta-analysis of the three available randomized trials of observation versus drainage of "occult pneumothorax" identified on CCT showed no difference between drainage and observation with regard to progression of the pneumothorax, the risk of pneumonia, or the length of stay in the hospital or ICU [37]. A caveat of this analysis is that the included studies primarily examined blunt trauma patients. A 
recent study by Ball and colleagues of patients specifically looked at occult pneumothoraces in patients with penetrating thoracic injuries. They found the incidence of occult pneumothorax to be $17 \%$, with only $56 \%$ of the occult pneumothoraces requiring chest tube drainage, compared to $95 \%$ of the overt pneumothoraces [38]. Thus, it appears that a trial observation is safe with asymptomatic occult pneumothoraces, even in penetrating trauma.

Patients with so-called "asymptomatic" penetrating chest injuries, where there is no evidence of intrathoracic on their initial workup, have posed a quandry in the past. Out of concern for possible delayed presentation of a hemothorax or pneumothorax, the traditional approach has been to observe these patients and obtain repeat chest radiographs after 3-6 h [39]. However, in a recent study by Berg et al. of 88 such patients, no clinically significant findings were found on late delayed CXR (median delay $7 \mathrm{~h} 16 \mathrm{~m}$ ) that were not also present on early delayed CXR (median delay $1 \mathrm{~h} 34 \mathrm{~m}$ ), suggesting that earlier follow-up imaging and shorter periods of observation are likely safe [40 $]$.

\section{Resuscitation of the Unstable or Severely Injured Patient}

Severely injured patients with penetrating chest trauma will generally present in one of two ways:

1. Profound hypotension due to:

a. Tension pneumothorax or cardiac tamponade (obstructive shock)

b. Exsanguination from great vessel injury, cardiac laceration, or intercostal artery laceration (hemorrhagic shock)

c. Arrhythmia or heart failure from blunt cardiac injury or coronary artery laceration (cardiogenic shock)

2. Profound hypoxia due to:

a. Major airway disruption (tracheobronchial injury)

b. Loss of functional alveoli due to extrinsic compression or intrapulmonary hemorrhage (pulmonary injury)

c. Disturbance of normal respiratory dynamics (chest wall injury)

Patients presenting in extremis or cardiac arrest after injury may be candidates for emergency department thoracotomy, depending on anatomic injury site, duration of pulselessness, cardiac rhythm, and ultrasound findings [41]. The absence of cardiac activity on ultrasonography has been shown to be a grave prognostic indicator in patients presenting with cardiac arrest $[42,43]$. Ferrada and colleagues have shown that the use of ultrasonography in the evaluation of patients in traumatic cardiac arrest is associated with a decrease in nontherapeutic thoracotomy [44•].
Shock after penetrating thoracic injury is typically due to bleeding, tension pneumothorax, or pericardial tamponade. A small subset of patients may have neurogenic shock related to spinal injury, but it is dangerous to assume this as the etiology of shock until other sources have been ruled out.

Tamponade can be diagnosed clinically, but the accuracy of bedside exam in this setting is variable. Beck's Triad, consisting of profound hypotension, elevated central venous pressure (or jugular venous distention), and muffled heart sounds, has a sensitivity that is excellent in some studies [45] and poor in others [46]. Tension pneumothorax can also present similarly, except with decreased breath sounds and tracheal deviation on exam. In the often noisy environment of the trauma bay, the detection of muffled heart sounds or decreased breath sounds can be challenging, especially in the setting of bilateral tension pneumothorax. As discussed earlier, E-FAST allows for rapid, accurate detection of hemothoraces, pneumothoraces, and hemopericardium and thus should immediately follow the primary survey. Intravenous access and fluid resuscitation can be initiated by another member of the team in parallel with this survey.

In the secondary survey, care should be taken to note all sites of penetration with the patient fully exposed, while another member of the team obtains a history, if able. Although this article focuses on penetrating thoracic injuries, patients can often have multiple wounds or mechanisms that can cause both blunt and penetrating injury. When forced to prioritize interventions for multiple injuries, it is helpful to keep in mind "what will kill the patient first?"

\section{Operative Indications in the Hypotensive Patient}

\section{Tension Pneumothorax}

Needle thoracostomy with an angiocath in second intercostal space (ICS) at the midclavicular line (MCL) has long been taught as a component of ATLS for relief of tension pneumothorax. This can be used as an initial temporizing measure, particularly in the pre-hospital setting; however, several reports have raised significant concerns regarding the effectiveness of needle decompression at relieving tension physiology. In the trauma bay, insertion of a chest tube is the definitive approach and can be performed nearly as expeditiously.

Several recent studies have questioned the appropriate site and device for emergent decomptression of tension pneumothorax. Cadaver [47], animal [48-50], and clinical [51-54] studies have suggested that use of a small $(3.2 \mathrm{~cm})$ needle in the standard site (second intercostal space, midclavicular line) is not reliable, likely due to the thickness of the chest wall at this site and the small size of the needle or catheter. Even when proper placement is confirmed laparoscopically in animal models, Martin and colleagues showed that a 14-gauge angiocatheter fails to relieve tension physiology $64 \%$ of the time [48]. The fourth or fifth intercostal space at the anterior 
axillary line is consistently thinner than the traditional site in multiple radiographic studies [52-54], which suggests that it may be a superior site for needle thoracostomy. Additionally, two groups have recently suggested borrowing techniques from laparoscopic abdominal surgery to avoid visceral injury as well as any problems with catheter kinking; Hatch and colleagues used 5-mm blunt laparoscopic trocars [49], while Lubin et al. suggest the use of a Veress needle with similar effect [50].

\section{Cardiac Tamponade}

Although cardiac tamponade is rapidly fatal when left untreated, prompt recognition and treatment can be lifesaving. In fact, in patients with stab wounds that present with cardiac tamponade, survival can be as high as $92 \%$ [27]. If tamponade is suspected, emergent surgical intervention is needed. In a spontaneously breathing patient with tamponade, intubation should be avoided until drainage is imminent, as positive pressure ventilation can further impair venous return and provoke cardiac arrest [55].

Pericardiocentesis is still taught in ATLS as a temporizing measure in situations where there may be a delay in definitive surgical care. Nonetheless, it appears to have fallen out of favor in recent years. Lee et al. recently published a meta-analysis showing that the use of pericardiocentesis in patients with suspected cardiac tamponade has decreased between 2000 and 2010, from 45.9 to $6.4 \%$ [56]. Intriguingly, Jones and colleagues have just reported a case series that raises the question of whether this procedure is underutilized. They looked retrospectively at a group of patients with tamponade who did or did not undergo ultrasound-guided percutaneous pericardial drain placement in the trauma bay prior to definitive surgical care. Insertion of the drain was not associated with any delay operative care, and in $59 \%$ of the patients, hypotension improved after drainage [57••]. While their study was underpowered to show a difference in mortality, there was a trend toward improved survival in the patients who underwent drain placement, which suggests an area for further research.

\section{Hemorrhagic Shock}

The indications for surgical management of noncardiac chest trauma have not changed in some time. While various volume cutoffs for chest tube drainage have been proposed, numbers are no substitute for sound clinical judgement. In hemodynamically unstable patients or those with evidence of massive hemorrhage (immediate drainage of $1000-1500 \mathrm{~mL}$ of blood through the tube, or large residual hemothorax on post-tube CXR), thoracotomy is indicated. Autotransfusion of blood drained by thoracostomy is practiced variably in a number of centers. This practice has been studied in the setting of postoperative cardiac surgery patients since the 1970 s as a means to possibly limit allogenic blood transfusion by reinfusion of shed mediastinal blood. There has been renewed interest in autotransfusion in trauma based on recent military experience suggesting a survival benefit to the transfusion of fresh whole blood [58-60]. Autotransfused blood has been shown to be safe, even in the presence of hollow viscus injury [61]. However, questions remain regarding the effectiveness of this practice at decreasing the need allogenic transfusion as well as the safety of autotransfusion of salvaged blood relative to allogenic transfusion of donor blood, particularly when directly reinfused without washing using a cellsaver device.

In trauma patients with hemothoraces, Salhanick et al. have shown that evacuated hemothorax differs significantly from whole blood; it is completely defibrinated, with high levels of fibrin degredation products, as well as decreased levels of coagulation factors, platelets, and red blood cells relative to venous blood [62]. In their study, it took $726 \mathrm{ml}$ of evacuated hemothorax to approximate the red cell content of $1 \mathrm{U}$ of packed red blood cells. Based on this finding, it appears likely that autotransfusion is clinically irrelevant in patients with less than 750-1000 $\mathrm{ml}$ of drainage, particularly if washing is performed prior to reinfusion.

Due to the lack of fibrinogen in evacuated hemothorax, it does not form clot in traditional coagulation assays such as the prothrombin time or partial thromboplastin time [62]. However, Smith and colleagues published the interesting observation that, when mixed with normal pooled plasma, the evacuated hemothorax fluid paradoxically induces a hypercoagulable state [63]; this was attributed to the presence of activated clotting factors within the hemothorax fluid. When the same group repeated this experiment using the patient's own plasma, the degree of induced hypercoagulability was even more pronounced [64].

Despite this hypercoagulopathy on traditional clotting assays, Konig and associates have shown that, on thromboelastography (TEG), salvaged blood actually induces a mixed state of factor hypercoagulability and platelet hypocoagulability when combined with the patient's own blood [65], with a $61 \%$ decrease in R-time and a $26 \%$ decrease in MA [65]. The platelet inhibition was attributed to competitive inhibition of platelet aggregation due to the high levels of fibrin degredation products in the salvaged blood. Unsurprisingly, both of these effects were reduced when the salvaged blood was washed first [65].

The relevance of these in vitro clotting abnormalities to the realm of patient care is unclear, as no existing studies have shown any clear benefit or harm to the practice of autotransfusion in trauma. While the above coagulation studies are intriguing, any theoretical risk also needs to be balanced against the real risks of autologous blood transfusion. 


\section{Cardiogenic Shock}

Only rarely will patients with penetrating chest trauma present with life-threatening arrhythmias secondary to a cardiac contusion. Nonetheless, blunt cardiac injury (BCI) after penetrating injuries to the chest has been described, particularly with high-velocity gunshot wounds [66]. This is possible due to the large amount of energy transferred into the tissues surrounding the bullet tract. Isolated injuries to the coronary arteries leading to acute myocardial infarction (AMI) without cardiac perforation or tamponade have also been reported [67, 68]. The evaluation and management of BCI have been recently reviewed in depth [69].

\section{Operative Indications in the Hypoxic Patient}

Many patients with profound hypoxia after penetrating chest trauma will require an airway; most will require tube thoracostomy [70]. Profound hypoxia immediately after penetrating chest trauma is most frequently due to pneumothorax or hemothorax, for which closed tube thoracostomy is lifesaving. Following chest tube insertion, a large or continuous air leak is suggestive of tracheobronchial injury. This is rare injury, occurring in only $1-2 \%$ of patients with penetrating thoracic injuries [71]. In addition, due to the proximity of the trachea and bronchi to other mediastinal structures, tracheobronchial injuries after penetrating chest trauma have a high incidence of associated injuries to the esophagus, spinal cord, heart, and great vessels. These associated injuries are frequently fatal (i.e., exsanguination from great vessel or cardiac injury) and often determine the ultimate outcome after injury.

In general, tracheobronchial injuries mandate early thoracotomy for repair due to inability to adequately ventilate the patient. Two recent case series have shown that selective conservative management of traumatic tracheobronchial injuries is possible with comparable outcomes to surgical repair [72, 73]. Patients amenable to conservative management include those with stable vital signs, effective ventilation if intubated or absence of respiratory distress if breathing spontaneously, nonprogressive mediastinal and/or subcutaneous emphysema, and absence of associated esophageal or major vascular injury. In these patients, management includes chest tube drainage, prophylactic antibiotics, and observation. Efforts should be made to characterize the nature of the injury using rigid or flexible bronchoscopy, prior to committing to a course conservative management, as large communication with the mediastinum may place the patient at risk for mediastinitis and should be considered an indication for surgical repair [73]; some authors are using CT virtual bronchoscopy for this purpose [72].
Traditionally, open pneumothorax was managed with application of a three-sided occlusive dressing that functioned as a flutter valve to vent any ongoing air leakage [74]. This is still taught in ATLS and until recently was recommended by the US Military Trauma Combat Casualty Care (TCCC) course [75]. There is little evidence of the effectiveness of these improvised dressings, and in recent years, numerous commercially available vented chest seals have been developed (Bolin, Asherman, HyFin, Russell, SAM, Sentinel), all of which incorporate some form of one-way valve to prevent development of tension pneumothorax. Several recent studies, including one from the US Army Institute of Surgical Research (USAISR), have demonstrated the effectiveness of vented chest seals at preventing the development of tension pneumothorax in animal models [76-78]. As such, recently published guidelines have endorsed the effectiveness of these products [74, 75, 79]. While these devices are an effective temporizing measure in the prehospital setting, such patients will ultimately require tube thoracostomy and reconstruction of the defect in the operating room.

Once the patient is intubated, if there is ongoing massive hemorrhage into the tracheobronchial tree, it is important to keep in mind that the immediate threat to life in this situation is typically due to asphyxia, not exsanguination. In these cases, emergency department or operating room thoracotomy will allow for pulmonary hilar cross-clamping to protect against further hemorrhage into the airway and prevent air embolism [80]. Direct surgical management of the pulmonary injury can then be undertaken.

\section{The Challenge of Thoracoabdominal Wounds}

Multiple authors have noted that incorrect sequencing in patients requiring dual-cavitary interventions is associated with large increases in mortality [81-83]; however, in most of these cases, death results from delayed recognition of a cardiac injury [81]. It is important to seek out evidence of PCI early. With thoracoabdominal wounds, it is easy to be mislead by chest tube output, either due to intraabdominal bleeding exiting the tube via a diaphragmatic defect or due to chest tubes clotting, thus concealing evidence of ongoing thoracic hemorrhage. In an older study, misleading chest tube output was found to be a frequent contributor to incorrect sequencing [82]. In the unstable patient with a thoracoabdominal wound, the determination of which cavity to explore first depends on the relative evidence of injury within the pericardium, thoracic cavity, and abdomen. When cardiac injury is present, most surgeons start with pericardial exploration. In the absence of cardiac injury, the choice between chest and abdomen is based on clinical exam and ultrasound findings. However, picking the initial site is less important than a rapid and flexible approach, wherein the first cavity is quickly evaluated and-if 
no source of massive hemorrhage is found-abandoned quickly in favor of exploration of the other cavity.

\section{Conclusions}

With penetrating injuries to the thorax, more than $85 \%$ of patients who present to the hospital alive can be successfully treated with attention to the ABCs of trauma care and tube thoracostomy when needed to evacuate hemothorax or pneumothorax. Nonetheless, injuries to the heart and lung have the potential to rapidly result in patient demise if not promptly recognized and treated appropriately. Ultrasonography is playing an increasing role in the evaluation of patients after thoracic injury to improve recognition of both pneumothorax and penetrating cardiac injuries.

\section{Compliance with Ethics Guidelines}

Conflict of Interest Drs. Scott and Sava declare that they have no conflicts of interest.

Human and Animal Rights and Informed Consent This article does not contain any studies with human or animal subjects performed by any of the authors.

\section{References}

Papers of particular interest, published recently, have been highlighted as:

- Of importance

-• Of major importance

1. Mollberg NM, Tabachnik D, Farjah F, Lin F-J, Vafa A, Abdelhady $\mathrm{K}$, et al. Utilization of cardiothoracic surgeons for operative penetrating thoracic trauma and its impact on clinical outcomes. Ann Thorac Surg. 2013;96(2):445-50. doi: 10.1016/j.athoracsur.2013. 04.033.

2. Poon H, Morrison JJ, Apodaca AN, Khan MA, Garner JP. The UK military experience of thoracic injury in the wars in Iraq and Afghanistan. Injury. 2013;44(9):1165-70. doi: 10.1016/j.injury. 2013.01.041.

3. Ivey KM, White CE, Wallum TE, Aden JK, Cannon JW, Chung KK, et al. Thoracic injuries in US combat casualties: a 10-year review of Operation Enduring Freedom and Iraqi Freedom. J Trauma Acute Care Surg. 2012;73(6 Suppl 5):S514-9. doi:10. 1097/TA.0b013e3182754654.

4. Keneally R, Szpisjak D. Thoracic trauma in Iraq and Afghanistan. J Trauma Acute Care Surg. 2013;74(5):1292-7. doi:10.1097/TA. 0b013e31828c467d.

5. Demetriades D, Kimbrell B, Salim A, Velmahos G, Rhee P, Preston $\mathrm{C}$, et al. Trauma deaths in a mature urban trauma system: is "trimodal" distribution a valid concept? J Am Coll Surg. 2005;201(3):343-8. doi:10.1016/j.jamcollsurg.2005.05.003.
6. Rhee PM, Foy H, Kaufmann C, Areola C, Boyle E, Maier R V, et al. Penetrating cardiac injuries: a population-based study. J Trauma. 1998;45(2):366-70.

7. Nandipati KC, Allamaneni S, Kakarla R, Wong A, Richards N, Satterfield J, et al. Extended focused assessment with sonography for trauma (EFAST) in the diagnosis of pneumothorax: experience at a community based level I trauma center. Injury. 2011;42(5):5114. doi: 10.1016/j.injury.2010.01.105.

8. Xirouchaki N, Magkanas E, Vaporidi K, Kondili E, Plataki M, Patrianakos A, et al. Lung ultrasound in critically ill patients: comparison with bedside chest radiography. Intensive Care Med. 2011;37(9):1488-93. doi:10.1007/s00134-011-2317-y.

9. Nagarsheth K, Kurek S. Ultrasound detection of pneumothorax compared with chest X-ray and computed tomography scan. Am Surg. 2011;77(4):480-4.

10. Hyacinthe A-C, Broux C, Francony G, Genty C, Bouzat P, Jacquot $\mathrm{C}$, et al. Diagnostic accuracy of ultrasonography in the acute assessment of common thoracic lesions after trauma. Chest. 2012;141(5): 1177-83. doi:10.1378/chest.11-0208.

11. Abbasi S, Farsi D, Hafezimoghadam P, Fathi M, Zare MA. Accuracy of emergency physician-performed ultrasound in detecting traumatic pneumothorax after a 2-h training course. Eur J Emerg Med. 2013;20(3):173-7. doi:10.1097/MEJ. 0b013e328356f754.

12. Jalli R, Sefidbakht S, Jafari SH. Value of ultrasound in diagnosis of pneumothorax: a prospective study. Emerg Radiol. 2013;20(2): 131-4. doi:10.1007/s10140-012-1091-7.

13. Ianniello S, Di Giacomo V, Sessa B, Miele V. First-line sonographic diagnosis of pneumothorax in major trauma: accuracy of e-FAST and comparison with multidetector computed tomography. Radiol Med. 2014;119(9):674-80. doi:10.1007/s11547-014-0384-1.

14. Ding W, Shen Y, Yang J, He X, Zhang M. Diagnosis of pneumothorax by radiography and ultrasonography: a meta-analysis. Chest. 2011;140(4):859-66. doi:10.1378/chest.10-2946.

15. Alrajhi K, Woo MY, Vaillancourt C. Test characteristics of ultrasonography for the detection of pneumothorax: a systematic review and meta-analysis. Chest. 2012;141(3):703-8. doi:10.1378/chest.11-0131.

16.• Alrajab S, Youssef AM, Akkus NI, Caldito G. Pleural ultrasonography versus chest radiography for the diagnosis of pneumothorax: review of the literature and meta-analysis. Crit Care. 2013;17(5), R208. doi:10.1186/cc13016. The most recent of three metaanalyses of ultrasound detection of pneumothoraces. The results indicate that ultrasonography is more accurate than chest radiography.

17. Rozycki GS, Feliciano DV, Ochsner MG, Knudson MM, Hoyt DB, Davis $\mathrm{F}$, et al. The role of ultrasound in patients with possible penetrating cardiac wounds: a prospective multicenter study. J Trauma. 1999;46(4):543-51. discussion 551-2.

18.• Nicol AJ, Navsaria PH, Beningfield S, Hommes M, Kahn D. Screening for occult penetrating cardiac injuries. Ann Surg. 2015;261(3):573-8. doi: 10.1097/SLA.0000000000000713. A prospective comparison of pericardial ultrasound to subxiphoid pericardial window (SPW) in $\mathbf{1 7 2}$ hemodynamically stable patients with penetrating chest trauma. Ultrasonography had a sensitivity of $87 \%$. The presence of right hemothorax and pneumomediastinum were confounding factors.

19. Ball CG, Williams BH, Wyrzykowski AD, Nicholas JM, Rozycki GS, Feliciano DV. A caveat to the performance of pericardial ultrasound in patients with penetrating cardiac wounds. J Trauma. 2009;67(5):1123-4. doi:10.1097/TA.0b013e3181b16f30.

20. Cull JD, Bokhari F. Penetrating chest injury in the setting of a hemothorax: should pericardial windows replace echocardiograms? Am Surg. 2013;79(2):E56-7.

21. Plurad DS, Bricker S, Van Natta TL, Neville A, Kim D, Bongard F, et al. Penetrating cardiac injury and the significance of chest 
computed tomography findings. Emerg Radiol. United States; 2013;20(4):279-84. doi: 10.1007/s10140-013-1113-0.

22. Bastos R, Baisden CE, Harker L, Calhoon JH. Penetrating thoracic trauma. Semin Thorac Cardiovasc Surg. 2008;20(1):19-25. doi: 10. 1053/j.semtcvs.2008.01.003.

23. Buckman RF, Badellino MM, Mauro LH, Asensio JA, Caputo C, Gass J, et al. Penetrating cardiac wounds: prospective study of factors influencing initial resuscitation. J Trauma. 1993;34(5): $717-25$.

24. Grewal H, Ivatury RR, Divakar M, Simon RJ, Rohman M. Evaluation of subxiphoid pericardial window used in the detection of occult cardiac injury. Injury. 1995;26(5):305-10. doi:10.1016/ 0020-1383(95)00029-9.

25. Meyer DM, Jessen ME, Grayburn PA. Use of echocardiography to detect occult cardiac injury after penetrating thoracic trauma: a prospective study. J Trauma. 1995;39(5):902-7.

26. Asensio JA, Roldan G, Petrone P, Forno W, Rowe V, Salim A. Cardiac trauma. Trauma. 2001;3(2):69-77. doi:10.1177/ 146040860100300201.

27. Degiannis E, Loogna P, Doll D, Bonanno F, Bowley DM, Smith MD. Penetrating cardiac injuries: recent experience in South Africa. World J Surg. 2006;30(7):1258-64. doi:10.1007/s00268-0050463-5.

28. Nicol AJ, Navsaria PH, Hommes M, Edu S, Kahn D. Management of a pneumopericardium due to penetrating trauma. Injury. 2014;45(9):1368-72. doi: 10.1016/j.injury.2014.02.017.

29. Smith CA, Galante JM, Pierce JL, Scherer LA. Laparoscopic transdiaphragmatic pericardial window: getting to the heart of the matter. J Am Coll Surg. 2011;213(6):736-42. doi: 10.1016/j. jamcollsurg.2011.09.005.

30. Thorson CM, Namias N, Van Haren RM, Guarch GA, Ginzburg E, Salerno TA, et al. Does hemopericardium after chest trauma mandate sternotomy? J Trauma Acute Care Surg. 2012;72(6):1515-8. doi: 10.1097/TA.0b013e318254306e.

31. Navsaria PH, Nicol AJ. Haemopericardium in stable patients after penetrating injury: is subxiphoid pericardial window and drainage enough? A prospective study. Injury. 2005;36(6):745-50. doi:10. 1016/j.injury.2004.08.005.

32. Nicol AJ, Navsaria PH, Hommes M, Ball CG, Edu S, Kahn D. Sternotomy or drainage for a hemopericardium after penetrating trauma: a randomized controlled trial. Ann Surg. 2014;259(3): 438-42. doi: 10.1097/SLA.0b013e31829069a1. This randomized controlled trial suggests that, for hemodynamically stable patients, the finding of hemopericardium at SPW may not mandate sternotomy in the absence of active hemorrhage.

33. Kong VY, Sartorius B, Clarke DL. The selective conservative management of penetrating thoracic trauma is still appropriate in the current era. Injury. 2014. doi:10.1016/j. injury.2014.07.011.

34. Inaba $\mathrm{K}$, Lustenberger $\mathrm{T}$, Recinos $\mathrm{G}$, Georgiou $\mathrm{C}$, Velmahos $\mathrm{GC}$, Brown C, et al. Does size matter? A prospective analysis of 28-32 versus 36-40 French chest tube size in trauma. J Trauma Acute Care Surg. 2012;72(2):422-7. doi: 10.1097/TA. 0b013e3182452444.

35.• Kulvatunyou N, Erickson L, Vijayasekaran A, Gries L, Joseph B, Friese RF, et al. Randomized clinical trial of pigtail catheter versus chest tube in injured patients with uncomplicated traumatic pneumothorax. Br J Surg. 2014;101(2):17-22. doi:10.1002/bjs.9377. This randomized controlled trial demonstrates that percutaneous catheter evacuation of traumatic pneumothorax is equally effective as compared to traditional chest tubes, with decreased pain at the insertion site.

36. Ball CG, Kirkpatrick AW, Feliciano DV. The occult pneumothorax: what have we learned? Can J Surg. 2009;52(5):E173-9.
37. Yadav K, Jalili M, Zehtabchi S. Management of traumatic occult pneumothorax. Resuscitation. 2010;81(9):1063-8. doi: 10.1016/j. resuscitation.2010.04.030.

38. Ball CG, Dente CJ, Kirkpatrick AW, Shah AD, Rajani RR, Wyrzykowski AD, et al. Occult pneumothoraces in patients with penetrating trauma: does mechanism matter? Can J Surg. 2010;53(4):251-5.

39. Seamon MJ, Medina CR, Pieri PG, Fisher CA, Gaughan JP, Bradley KM, et al. Follow-up after asymptomatic penetrating thoracic injury: 3 hours is enough. J Trauma. 2008;65(3):549-53. doi: 10.1097/TA.0b013e31817fa463.

40. Berg RJ, Inaba K, Recinos G, Barmparas G, Teixeira PG, Georgiou $\mathrm{C}$, et al. Prospective evaluation of early follow-up chest radiography after penetrating thoracic injury. World J Surg. 2013;37(6):128690. doi:10.1007/s00268-013-2002-0. This is a prospective evaluation of 87 asymptomatic patients without evidence of injury on initial evaluation after penetrating thoracic injuries, comparing early follow-up CXR (median interval 1 hr 35 mins) to delayed follow-up (median interval $7 \mathrm{hr} 16$ mins). No significant findings were noted on delayed imaging that were not detected on the early follow-up CXR.

41. Burlew CC, Moore EE, Moore FA, Coimbra R, McIntyre RC, Davis JW, et al. Western Trauma Association critical decisions in trauma: resuscitative thoracotomy. J Trauma Acute Care Surg. 2012;73(6):1359-63. doi: 10.1097/TA.0b013e318270d2df.

42. Schuster KM, Lofthouse R, Moore C, Lui F, Kaplan LJ, Davis KA. Pulseless electrical activity, focused abdominal sonography for trauma, and cardiac contractile activity as predictors of survival after trauma. J Trauma. 2009;67(6):1154-7. doi:10.1097/TA. 0b013e3181c303e8.

43. Cureton EL, Yeung LY, Kwan RO, Miraflor EJ, Sadjadi J, Price $\mathrm{DD}$, et al. The heart of the matter: utility of ultrasound of cardiac activity during traumatic arrest. J Trauma Acute Care Surg. 2012;73(1):102-10. doi: 10.1097/TA.0b013e3182569ebc.

44. Ferrada P, Wolfe L, Anand RJ, Whelan J, Vanguri P, Malhotra A, et al. Use of limited transthoracic echocardiography in patients with traumatic cardiac arrest decreases the rate of nontherapeutic thoracotomy and hospital costs. J Ultrasound Med. 2014;33(10):1829 32. doi:10.7863/ultra.33.10.1829. A retrospective case series demonstrating that the use of ultrasonography in the evaluation of patients in traumatic cardiac arrest is associated with a decrease in non-therapeutic thoracotomy.

45. Demetriades D. Cardiac wounds. Experience with 70 patients. Ann Surg. 1986;203(3):315-7.

46. Demetriades D, van der Veen BW. Penetrating injuries of the heart: experience over two years in South Africa. J Trauma. 1983;23(12): 1034-41.

47. Inaba K, Branco BC, Eckstein M, Shatz DV, Martin MJ, Green DJ, et al. Optimal positioning for emergent needle thoracostomy: a cadaver-based study. J Trauma. 2011;71(5):1099-103. doi:10. 1097/TA.0b013e31822d9618.

48. Martin M, Satterly S, Inaba K, Blair K. Does needle thoracostomy provide adequate and effective decompression of tension pneumothorax? J Trauma Acute Care Surg. 2012;73(6):1412-7. doi:10. 1097/TA.0b013e31825ac511.

49. Hatch Q, Debarros M, Johnson E, Inaba K, Martin M. Standard laparoscopic trocars for the treatment of tension pneumothorax: a superior alternative to needle decompression. J Trauma Acute Care Surg. 2014;77(1):170-5. doi:10.1097/TA.0000000000000249.

50. Lubin D, Tang AL, Friese RS, Martin M, Green DJ, Jones T, et al. Modified Veress needle decompression of tension pneumothorax: a randomized crossover animal study. J Trauma Acute Care Surg. 2013;75(6):1071-5. doi:10.1097/TA.0b013e318299563d.

51. Ball CG, Wyrzykowski AD, Kirkpatrick AW, Dente CJ, Nicholas $\mathrm{JM}$, Salomone JP, et al. Thoracic needle decompression for tension 
pneumothorax: clinical correlation with catheter length. Can J Surg. 2010;53(3):184-8.

52. Lamblin A, Turc J, Bylicki O, Lohéas D, Martinez J-Y, Derkenne C, et al. Measure of chest wall thickness in French soldiers: which technique to use for needle decompression of tension pneumothorax at the front? Mil Med. 2014;179(7):783-6. doi:10.7205/ MILMED-D-13-00512.

53. Inaba $\mathrm{K}$, Ives $\mathrm{C}, \mathrm{McClure} \mathrm{K}$, Branco $\mathrm{BC}$, Eckstein $\mathrm{M}$, Shatz $\mathrm{D}$, et al. Radiologic evaluation of alternative sites for needle decompression of tension pneumothorax. Arch Surg. 2012;147(9):813-8. doi:10.1001/archsurg.2012.751.

54. Chang SJ, Ross SW, Kiefer DJ, Anderson WE, Rogers AT, Sing RF, et al. Evaluation of $8.0-\mathrm{cm}$ needle at the fourth anterior axillary line for needle chest decompression of tension pneumothorax. J Trauma Acute Care Surg. 2014;76(4):1029-34. doi:10.1097/TA. 0000000000000158.

55. Barthélémy R, Bounes V, Minville V, Houze-Cerfon C-H, Ducassé J-L. Prehospital mechanical ventilation of a critical cardiac tamponade. Am J Emerg Med. 2009;27(8):1020.e1-3. doi: 10. 1016/j.ajem.2008.12.024.

56. Lee TH, Ouellet J-F, Cook M, Schreiber MA, Kortbeek JB. Pericardiocentesis in trauma: a systematic review. J Trauma Acute Care Surg. 2013;75(4):543-9. doi: 10.1097/TA. 0b013e3182a1fea2.

57.• Jones TS, Burlew CC, Stovall RT, Pieracci FM, Johnson JL, Jurkovich GJ, et al. Emergency department pericardial drainage for penetrating cardiac wounds is a viable option for stabilization. Am J Surg. 2014;207:931-4. A small retrospective review that suggests there may still be a role for percutaneous pericardial drainage in the trauma bay. Drain insertion appeared to improve hemodynamics without introducing signicant delays in surgical care. The study was underpowered to show a mortality benefit.

58. Spinella PC. Warm fresh whole blood transfusion for severe hemorrhage: U.S. military and potential civilian applications. Crit Care Med. 2008;36(7 Suppl):S340-5. doi:10.1097/CCM.0b013e31817e2ef9.

59. Spinella PC, Perkins JG, Grathwohl KW, Beekley AC, Holcomb JB. Warm fresh whole blood is independently associated with improved survival for patients with combat-related traumatic injuries. J Trauma. 2009;66(4 Suppl):S69-76. doi:10.1097/TA. $0 \mathrm{~b} 013 \mathrm{e} 31819 \mathrm{~d} 85 \mathrm{fb}$.

60. Holcomb JB, Spinella PC. Optimal use of blood in trauma patients. Biologicals. 2010;38(1):72-7. doi: 10.1016/j.biologicals.2009.10. 007.

61. Caliste XA, McArthur KA, Sava JA. Autotransfusion in emergent operative trauma resuscitation. Eur J Trauma Emerg Surg. 2014;40(5):541-5. doi:10.1007/s00068-013-0328-9.

62. Salhanick M, Corneille M, Higgins R, Olson J, Michalek J, Harrison C, et al. Autotransfusion of hemothorax blood in trauma patients: is it the same as fresh whole blood? Am J Surg. 2011;202(6):817-21; discussion 821-2. doi: 10.1016/j.amjsurg. 2011.06.043.

63. Smith WZ, Harrison HB, Salhanick M a, Higgins R a, Ortiz A, Olson JD, et al. A small amount can make a difference: a prospective human study of the paradoxical coagulation characteristics of hemothorax. Am J Surg. 2013;206(6):904-9; discussion 909-10. doi: 10.1016/j.amjsurg.2013.08.004.

64. Harrison HB, Smith WZ, Salhanick MA, Higgins RA, Ortiz A, Olson JD, et al. An experimental model of hemothorax autotransfusion: impact on coagulation. Am J Surg. 2014;208(6):1078-82. doi: 10.1016/j.amjsurg.2014.09.012.

65. Konig G, Yazer MH, Waters JH. The effect of salvaged blood on coagulation function as measured by thromboelastography. Transfusion. 2013;53(6):1235-9. doi:10.1111/j.1537-2995.2012. 03884.x.

66. Ferrada PA, Parrish DW. Gunshot wound to the box: a threat even on a stable patient. Ivatury Richmond RR, editor. Panam J Trauma,
Crit Care Emerg Surg. 2012;1(August):137-8. doi: 10.5005/jpjournals-10030-1030.

67. Bartoloni G, Trio F, Bartoloni A, Giorlandino A, Pucci A. A fatal stab wound causing selective injury to the left anterior descending coronary artery, myocardial infarction and delayed cardiac tamponade. Forensic Sci Int. 2013;229(1-3):e16-8. doi: 10.1016/ j.forsciint.2013.03.023.

68. Elms AR, Wong G, Wisner D, Bair A. Myocardial ischemia with penetrating thoracic trauma. West J Emerg Med. 2011;12(2):224-6.

69. Yousef R, Carr JA. Blunt cardiac trauma: a review of the current knowledge and management. Ann Thorac Surg. 2014;98(3):1134 40. doi: 10.1016/j.athoracsur.2014.04.043.

70. Feliciano DV. The diagnostic and therapeutic approach to chest trauma. Semin Thorac Cardiovasc Surg. 1992;4(3):156-62.

71. Karmy-Jones R, Wood DE. Traumatic injury to the trachea and bronchus. Thorac Surg Clin. 2007;17(1):35-46. doi:10.1016/j. thorsurg.2007.03.005.

72. Alassal MA, Ibrahim BM, Elsadeck N. Traumatic intrathoracic tracheobronchial injuries: a study of 78 cases. Asian Cardiovasc Thorac Ann. 2014;22(7):816-23. doi:10.1177/0218492313516777.

73. Carretta A, Melloni G, Bandiera A, Negri G, Voci C, Zannini P. Conservative and surgical treatment of acute posttraumatic tracheobronchial injuries. World J Surg. 2011;35(11):2568-74. doi:10. 1007/s00268-011-1227-Z.

74. Lee C, Revell M, Porter K, Steyn R. The prehospital management of chest injuries: a consensus statement. Faculty of Pre-hospital Care, Royal College of Surgeons of Edinburgh. Emerg Med J. 2007;24(3):220-4. doi:10.1136/emj.2006.043687.

75. Butler FK, Dubose JJ, Otten EJ, Bennett DR, Gerhardt RT, Kheirabadi BS, et al. Management of open pneumothorax in tactical combat casualty care: TCCC guidelines change 13-02. J Spec Oper Med. 2013;13(3):81-6.

76. Kotora JG, Henao J, Littlejohn LF, Kircher S. Vented chest seals for prevention of tension pneumothorax in a communicating pneumothorax. J Emerg Med. 2013;45(5):686-94. doi: 10.1016/j. jemermed.2013.05.011.

77. Arnaud F, Tomori T, Teranishi K, Yun J, McCarron R, Mahon R. Evaluation of chest seal performance in a swine model: comparison of Asherman vs Bolin seal. Injury. 2008;39(9):1082-8. doi:10. 1016/j.injury.2008.03.003.

78. Kheirabadi BS, Terrazas IB, Koller A, Allen PB, Klemcke HG, Convertino VA, et al. Vented versus unvented chest seals for treatment of pneumothorax and prevention of tension pneumothorax in a swine model. J Trauma Acute Care Surg. 2013;75(1):150-6. doi: 10.1097/TA.0b013e3182988afe.

79. Walthall K. Towards evidence-based emergency medicine: best BETs from the Manchester Royal Infirmary. BET 3: in a penetrating chest wound is a three-sided dressing or a one-way chest seal better at preventing respiratory complications? Emerg Med J. 2012;29(4): 342-3. doi:10.1136/emermed-2012-201159.4.

80. Van Natta TL, Smith BR, Bricker SD, Putnam BA. Hilar control in penetrating chest trauma: a simplified approach to an underutilized maneuver. J Trauma. 2009;66(6):1564-9. doi:10.1097/TA. 0b013e31817fdf2d.

81. Clarke DL, Gall TMH, Thomson SR. Double jeopardy revisited: clinical decision making in unstable patients with, thoracoabdominal stab wounds and, potential injuries in multiple body cavities. Injury. 2011;42(5):478-81. doi: 10.1016/j.injury.2010.06. 027.

82. Hirshberg A, Wall MJ, Allen MK, Mattox Jr KL. Double jeopardy. J Trauma. 1995;39(2):225-31. doi:10.1097/00005373-19950800000007.

83. Asensio J, Arroyo H, Veloz W, Forno W, Gambaro E, Roldan G, et al. Penetrating thoracoabdominal injuries: ongoing dilemmawhich cavity and when? World J Surg. 2002;26(5):539-43. doi: 10.1007/s00268-001-0147-8. 